confined to babies three to six months old. It is infectious in close communities; but the same serotypes are found universally. These serotypes may differ slightly in their biochemical characteristics; but fundamentally they are all typical $E$. coli. At the same time, they may have serological identities with certain of the Salmonella group. So what of their classification?

These papers will be published in full at a later date in the Journal of Applied Bacteriology.

\section{INTERNATIONAL LIGHT METALS CONGRESS AT LEOBEN}

$\mathrm{T}$

HE international Light Metals Congress, held in Leoben, Austria, during June 7-9, was the third such meeting there, the previous ones being in 1934 and 1948, and as on the former occasions, the purpose of the Congress was to give a comprehensive picture of the present state of the light metals industry and to permit informal discussion and exchange of views among the delegates. Organized by the Montanistische Hochschule with the assistance of the Austrian light metals industry, the Congress was attended by more than three hundred and fifty representatives from nineteen countries. The programme included an exhibition of the applications of aluminium, various visits and social functions, and six technical sessions at which more than thirty papers woro read. In addition to the usual facilities for lantern slides and films, arrangements were made for the whole proceedings to be televised to a second audience in the overflow meetings.

The opening session was devoted to reviewing the part played by light metals in the economy of the major countries represented, which included Austria, France, Great Britain and the British Commonwealth, Italy, the German Federal Republic, Switzer. land and the United States. The papers were contributed by W. C. Binz, R. Carmina, 'Th. Dirksen, A. Dumas, F. C. Frary, B. K. Klein, G. V. Schulthess and W. J. Thomas, respectively. All told. much the same story of rapid post-war growth of the industry, encouraged by the continuing strong demand for light metal products. An interesting fact brought out by these papers is that the present and estimated future demand for aluminium exceeds existing supplies of electrical energy and bauxite-the chief raw materials of the industry - so that attention is being turned to additional sources, notably those in undeveloped areas of western Canada and Africa.

In the session dealing with advances in metallurgy, M. O. Sem (Oslo) described the importance of the Söderberg electrode in modern large electrolytic cells, and P. Gross (Stoke Poges) examined the conditions to be fulfilled in the sub-halide distillation of aluminium. A. Brenner (Lend) gave an account of the production, properties and uses of super-purity aluminium - a material which is of growing industrial importance. The single paper devoted to magnesium was presented by C. J. P. Ball (London); this was a comparative survey of the methods currently used for the extraction of magnesium.

Interest in titanium, the latest member of the light metals family to be used industrially, was evidenced by the five papers dealing with this metal. Two of these described extraction processes: R. Kicffer (Reutte) summarized the present methods of production, with figures illustrating the astonishing growth in output during the past few years, and E. Fitzer, H. Hofbauer and $H$. Hohn gave an account of a process in which an alkali amalgam is used to reduce titanium tetrachloride to titanium amalgam, the mercury being afterwards removed by distillation. M. Hansen (Frankfurt) dealt with the physical metallurgy of titanium and its alloys.

An encouraging sign of improved international relations was the participation of scientists from the U.S.S.R., who contributed two papers on the metallurgy of titanium alloys, including one by Dr. M. A. Pavlov, of the Moseow Academy of Sciences.

Papers dealing with the technology of light metals included one on foundry practice by Prof. A. von Zeerleder, a pioneer of the light metals industry, who discussed the advances in foundry technique from the historical point of view, with emphasis on recent improvements in gating systems. K. Schneider (Nuremberg) described the methods used in the recovery and treatment of secondary metals, and $\mathbf{M}$. Lamourdedieu (Paris) dealt with current practice in the rolling of light metals. Much interest was aroused by R. D. Hamer's paper on experience with the continuous casting and rolling of aluminium strip, which was supported by a short film depicting the operation of installations at Rorschach and Banbury. During recent years a demand has arisen from the aircraft industry for large structural forgings to replace members which otherwise would be built up from extmusions and sheet, and $G$. W. Richards and C. Wilson (Birmingham) discussed some of the metallurgical problems which arise in the production of these forgings, particularly the control of internal stresses. An account of recent advances in welding practice, including inert gas welding, cold welding and the high-frequency welding of tubes, was given by E. Zurbrügg (Neuhausen), and G. Luft and F. Sacchi (Novara) read a paper on surface treatment with reference to Italian exporience.

Six papers were devoted to topics in physical metallurgy and metallography. R. Mitsche (Leoben) described the effect of superheating on the structure of as-cast metals, while E. M. Onitsch-Modl (Winterthur) surveyed the powder metallurgy of aluminium, magnesium and titanium. P. Brenner (Lend) discussed an urgent engineering problem, that of the fatigue strength of aluminium alloys and its relation to other properties of the material. The connexion between processing conditions and the properties of extrusions was considered by E. Nachtigall (Ranshofen), and G. Siebel (Singen) discussed a perennial production problem - the earing of certain aluminium alloys during deep drawing and the influence of processing variables on this behaviour. E. Schmid (Vienna) contributed a necessarily brief account of the part played by lithium, beryllium, magnesium, aluminium, silicon and titanium in certain applications to physics, with particular reference to nuclear energy.

The final session was devoted to applications of the light metals. 'The way in which new applications are evolved, developed and finally established was discussed by de Ridder, and M. Langegger (Ranshofen) described the various applications of semifinished products in Austria. L. Kirste (Vienna) examined the essential requirements to be met for successful light-weight construction, and C. Panseri (Novara) mentioned some of the problems which arise when aluminium is used in architecture; he also described a new magnesium-silicide alloy whioh has been developed in Italy for spandrel sections. A 
comprehensive paper on the use of aluminium for transport by land, sea and air was contributed by J. J. Baron (Paris), in which details were given of the various applications. A. Taranger (Oslo) discussed another field of use, that of rigid wall cans for processed foods; he concluded that the technical obstacles to the use of aluminium in canning have been largely overcome, and therefore wider employ. ment is a matter of economics. J. C. Bailey (London) dealt with electrical engineering, a field in which aluminium has made, and is still making, great strides and in which it occupies a favourable economic position.

In addition to the foregoing, the following papers were submitted in summary form : improvements in the quality of aluminium-silicon alloys (W. Thury); reactivity and specific consumption of anode carbon in the industrial electrolytic production of aluminium (A. Vajna de Pava); and chemical background to the wet alkaline process of Bayer for extracting aluminium oxide hydrate from bauxites (F. Heyd).

The full text of all the papers will be published, in German, in the journals Aluminium (AluminiumVerlag GmbH., Düsseldorf) and Berg- und Hüttenmännischen Monatsheften (Springer-Verlag, Vienna) this autumn.

\section{THE MEDICAL RESEARCH COUNCIL REPORT FOR 1954-55}

$\mathrm{T}$ HE report of the Medical Research Council for the year $1954-55^{*}$ follows the plan used in recent years of giving summaries only of the work of the Council's many research establishments, the main part of the report being devoted to a discussion of selected aspects of the general trend of medical research. As the report emphasizes, every conspicuous advance in medical research depends on $a_{0}$ mass of unspectacular work and on team work, to which every individual taking part, whatever his status, contributes essential skill or knowledge.

Among the subjects selected for discussion this year the control of poliomyelitis is of popular interest, and an account is given of the vaccines now in use as prophylactics against this disease. The results of the American trial of the Salk vaccine, so admirably conducted, showed that this vaccine reduced paralytic poliomyelitis among children aged 6-9 years by 28 per cent, the protection increasing with age. After revision of the safety tests, many millions of children in the United States and Canada have been vaccinated. The report describes the work being done in Britain on the manufacture of a somewhat different vaccine and on tests of its safety and on trials of it. It then goes on to discuss the epidemiology of poliomyelitis and the increased risk of development of the disease in children who have recently been inoculated with a combined prophylactic against diphtheria and whooping-cough or who have recently had their tonsils removed.

Other subjects discussed in this part of the report are recent research on influenza, vaccination against tuberculosis, antibody immunity, the mechanism of allergic reactions, the causes and control of odema due to diseases of the kidneys, human genetics, developments in biophysics and the fallacies of the design of industrial work.

* Committee of Privy Council for Medical Research. Report of the Medical Research Council for the Year 1954-55. (Cmd. 9787.) Pp. $\mathrm{v}+286$. (London: H.M.S.O., 1956.) 10s. net.
The rest of the report, after outlining the administration of the Council's work, epitomizes its research programme and gives the names of its personnel, summaries of the programmes of the many research units and a list of the many publications reporting the work of the Council's staff and the work of the staffs of the Institute of Cancer Research and the Public Health Laboratory Service. The report is, in fact, a complete guide to the Council's many-sided activities. It would be hard to find anywhere a finer record of the devoted efforts of many people of different skills to better the health of man to-day and to make the world a better place for generations to come.

G. LAPAGE

\section{CRYSTALLINE CYTOCHROME C}

\section{Preparation of Crystalline Cytochrome c from Yeast}

THE first crystallization of cytochrome $c$ was reported from muscle of the king penguin by (7. Bodo ${ }^{1}$. Cytochrome $c$ has been crystallized by us from more convenient sources, such as baker's yeast, beef heart ${ }^{2}$ or pig heart ${ }^{2}$. In this communication is reported the isolation from yeast of crystalline cytochrome $c$, which was shown to be a homogeneous protein by electrophoretic, ultracentrifugal and chromatographic criteria ${ }^{2}$.

Baker's yeast, treated with ethylacetate (1/7 vol.) for one hour, was twice washed by suspending in tap water (5 vol.) for one hour while keeping the suspension at $p \mathrm{H}$ 7-8 with ammonia. The washed yeast was twice extracted with 10 per cent ammonium sulphate solution (the same volume as the yeast cake) for fifteen hours. The ratio of extinction at $550 \mathrm{~m} \mu$ of the reduced pigment to the extinction of $280 \mathrm{~m} \mu$ of oxidized pigment which is abbreviated to $R_{280}^{550}$ was $0 \cdot 01$. The extract, after being dialysed against tap water for two days, was passed through a column of cation exchange resin, 'Duolite CS-101' (buffered at $p \mathrm{H} 7 \cdot 0$ ), which has a greater capacity for adsorption of cytochrome $c$ than the 'Amberlite' IRC-50 (XE-64) ordinarily used ${ }^{3-5}$. After washing the column with dilute ammonium sulphate solution $(0.05 M)$, the cytochrome $c$ was eluted with 0.2 saturated ammonium sulphate solution (eluate: $R_{280}^{550}=0 \cdot 2-0 \cdot 3$ ). The solution containing about 0.05 per cent oxidized cytochrome $c$ was saturated with ammonium sulphate at $p \mathrm{H} 5 \cdot 0$ and the resulting precipitate was removed (filtrate : $R_{280}^{s s 0}=0 \cdot 4-0 \cdot 7$ ). The filtrate was dialysed and cytochrome $c$ further concentrated using $C S-101$ as before except that ammonium phosphate buffer solution $(1 \cdot 0 M, p H .7 \cdot 0)$ was used for the elution.

The cytochrome $c$ was purified by the method of Margoliash ${ }^{4}$ with some modification in which the resin, $X E^{\prime}-64$, treated with sodium hypochlorite and ammonium phosphate buffer solution $(0 \cdot 4 M, p H ~ 7 \cdot 0)$ was used. The cytochrome $c$ eluted in the oxidized form at about four hold up volumes was collected and highly concentrated using a small column of $C S-101$ (eluate: $R_{280}^{550} \doteqdot 1 \cdot 15$ ). The solution, containing more than 10 per cent oxidized cytochrome $c$, was nearly saturated (about 0.85 saturation) with ammonium sulphate at $p H 5 \cdot 0$ and the slight amount of resulting precipitate was removed (supernatant: $\left.R_{280}^{550} \doteqdot 1 \cdot 2\right)$. 